\title{
Mechanical performance of aerated concrete and its bonding performance with glass fiber grille
}

https://doi.org/10.1515/nleng-2021-0018

Received May 13, 2021; accepted Jun 28, 2021.

\begin{abstract}
This paper studied the mechanical performance of aerated concrete and its bonding performance with glass fiber grille, and explores the influence of aluminum powder and aluminum powder on mechanical performance and bonding performance. The results showed that the compressive strength of aerated concrete decreased with the increase of aluminum powder content, while it first increased and then decreased with the increase of ferrosilicon alloy powder content. The failure modes of specimens were fiber fracture failure, and the fibers were not pulled out from the aerated concrete. It can provide a theoretical basis for the application of aerated concrete and glass fiber in engineering.
\end{abstract}

Keywords: aerated concrete, compressive strength, bonding strength, glass fiber grille, aluminum powder, ferrosilicon alloy powder

\section{Introduction}

At present, the prefabricated building structure system has been vigorously promoted. As vertical non-load-bearing component, internal and external partition wall panels are widely used in prefabricated building structures. Aerated concrete wall panels have light weight, good thermal insulation performance, strong seismic performance, good processing performance, inevitable high temperature resistance, good sound insulation performance, and strong adaptability are widely used.

\footnotetext{
Zhenfang Li, Dong Gao, Chuanji Wu, Guoqing Lv, Xin Liu, Shandong Hi-speed Urban \& Rural Development Group CO., LTD, Jinan, Shangdong, China, 250014

*Corresponding Author: Haoran Zhai, Shandong Hi-speed Urban \& Rural Development Group CO., LTD, Jinan, Shangdong, China, 250014, E-mail: 1294191132@qq.com

*Corresponding Author: Zhanfang Huang, Shandong University of Technology, School of Civil and Architectural Engineering, 266 Xincun West Road, Zibo, Shangdong, China, 255000, E-mail: huangzhanfang@163.com
}

Alexanderson et al. [1], Petrov et al. [2] and Prim et al. [3] investigated the micro-structure of aerated concrete and found that the pore structure of aerated concrete was mainly divided into two levels: micro-pore structure and macro-pore structure, and analyzed the formation of pore structure. Wang et al. [4], Robler et al. [5] and Ho et al. [6] investigated the influencing factors of the compressive strength of aerated concrete. Varela et al. [7] analyzed autoclaved aerated concrete block shear wall through quasistatic test, and developed relevant applications to optimize the structural design of autoclaved aerated concrete. Tomá [8] studied the shrinkage and damage phenomena of aerated concrete through experiments and carried out numerical simulation analysis on this basis. The research showed that the experimental phenomena of numerical simulation analysis were basically consistent with the experimental values. Yu [9] investigated the mechanical properties, failure phenomena and failure principle of aerated concrete block wall by quasi-static test. Jin [10] studied the bearing capacity of connection joints of aerated concrete wallboard under different factors through experiments. Leng [11] studied the bending performance of autoclaved aerated concrete slab under load through experiments, and deduced the calculation formula of ultimate bending moment according to the failure mode of slab and test data. Wu [12] studied conducted nonlinear analysis on autoclaved aerated concrete block wall using ABAQUS finite element simulation software. Zeng et al. [13] analyzed the stress-strain curve of autoclaved aerated concrete block under uniaxial compression through experimental research and theoretical analysis. Li [14] carried out experimental and theoretical studies on several connection joints of autoclaved aerated concrete wallboard, and analyzed the failure mode and the bearing capacity. Zhang et al. [15] studied the variation of ultimate bearing capacity of autoclaved aerated concrete slabs. Li [16] studied enhancing carbonation and chloride resistance of autoclaved concrete by incorporating $\mathrm{Nano}-\mathrm{CaCO}_{3}$.

The tensile properties of wall panels are mostly improved by setting steel bars in aerated concrete. However, as a traditional ductile material, steel bars have disadvantages such as self-weight and poor corrosion resistance. If a fiber-forming material can be used to replace traditional 
steel bars, it can not only reduce the weight of the wall fiber is a good choice.

Furthermore, good bonding performance between glass fiber grille and aerated concrete is the premise of their joint work [17]. It is necessary to study the bonding performance of glass fiber grille and aerated concrete. However, there is few studies focused on the bonding performance of aerated concrete and glass fiber grille.

The purpose of this paper is to investigate the mechanical performance of aerated concrete and its bonding performance with glass fiber grill, obtain the influence of aluminum powder and ferrosilicon alloy powder on $\mathrm{cu}$ bic compressive strength on cubic compressive strength of aerated concrete, and obtain the bonding force between aerated concrete and glass fiber grill. The graphical abstract is shown in Figure 1.

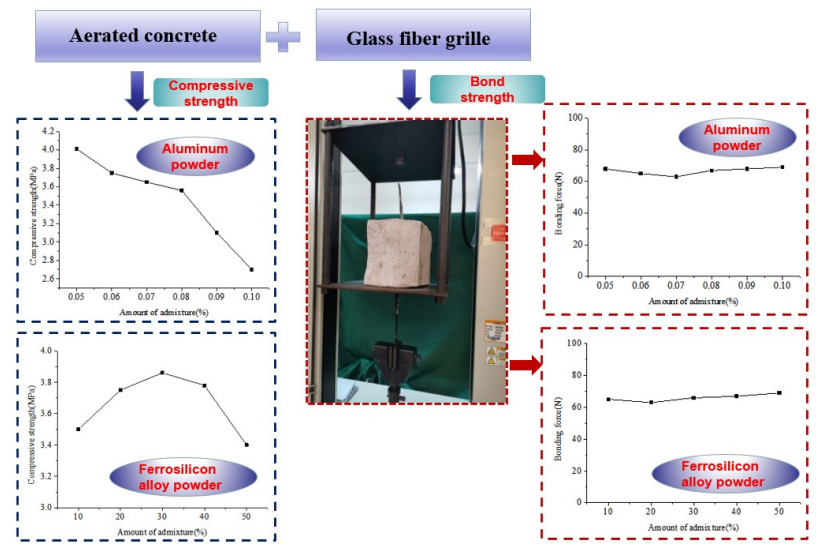

Figure 1: Graphical abstract panel, but also improve its durability. High-strength glass

mix proportions of aerated concrete is 0.52 , and the basis mix proportions are listed in Table 5. The glass fiber properties are listed in Table 6.

Table 1: Cement properties

\begin{tabular}{cc}
\hline Property & Value \\
\hline Specific surface area $\left(\mathrm{m}^{2} \mathrm{~kg}^{-1}\right)$ & 335 \\
Initial setting times $(\mathrm{min})$ & 130 \\
Final setting times (min) & 215 \\
28-day compressive strength (MPa) & 45.8 \\
28-day flexural strength (MPa) & 7.5 \\
$\mathrm{SO}_{3}(\%)$ & 2.35 \\
$\mathrm{MgO}(\%)$ & 1.67 \\
\hline
\end{tabular}

Table 2: Chemical composition of desulfurized gypsum (\%)

\begin{tabular}{cc}
\hline Property & Value \\
\hline $\mathrm{CaO}$ & 40 \\
$\mathrm{SO}_{2}$ & 2.75 \\
$\mathrm{SO}_{3}$ & 34 \\
$\mathrm{MgO}$ & 0.45 \\
\hline
\end{tabular}

Table 3: Chemical composition of lime (\%)

\begin{tabular}{cc}
\hline Property & Value \\
\hline $\mathrm{CaO}$ & 76.57 \\
$\mathrm{MgO}$ & 3.62 \\
$\mathrm{SO}_{2}$ & 5.42 \\
$\mathrm{SO}_{3}$ & 0.43 \\
$\mathrm{Al}_{2} \mathrm{O}_{3}$ & 3.96 \\
\hline
\end{tabular}

Table 4: Chemical composition of fly ash (\%) tures was P.O 42.5 Portland cement, the cement properties are listed in Table 1. Desulphurized gypsum was homogenized and milled by ball mill before use. The chemical composition of desulfurized gypsum is listed in Table 2. Lime meets the requirements of JC/T621-2009 [18]. The chemical composition of lime are shown in Table 3. The chemical composition of fly ash is shown in the Table 4. The active aluminum content of aluminum paste is $83 \%$, and the solid content is $74 \%$. The water to material ratio of

\section{Experiment}

\subsection{Materials and mix proportions}

In this study, the cement type used for the concrete mix-

\begin{tabular}{cc}
\cline { 2 - 2 } Property & Value \\
\cline { 2 - 3 } $\mathrm{CaO}$ & 8.10 \\
$\mathrm{MgO}$ & 1.49 \\
$\mathrm{SO}_{2}$ & 57.30 \\
$\mathrm{SO}_{3}$ & 0.18 \\
$\mathrm{Al}_{2} \mathrm{O}_{3}$ & 21.40 \\
\hline
\end{tabular}

Table 5: Basis mix proportions (\%)

\begin{tabular}{cc}
\hline Material type & Value \\
\hline Cement & 70 \\
Desulfurized gypsum & 4.5 \\
Lime & 14.5 \\
Fly ash & 11 \\
\hline
\end{tabular}


Table 6: Glass fiber grille properties

\begin{tabular}{cc}
\hline Property & Value \\
\hline Radial fracture strength $(\mathrm{kN} / \mathrm{m})$ & 50 \\
Latitudinal fracture strength $(\mathrm{kN} / \mathrm{m})$ & 50 \\
Radial breaking elongation $(\%)$ & 4 \\
Latitudinal breaking elongation $(\%)$ & 4 \\
\hline
\end{tabular}

\subsection{Specimens}

The specimens $(150 \mathrm{~mm} \times 150 \mathrm{~mm} \times 150 \mathrm{~mm})$ were used to test the cubic compressive strength of aerated concrete; The pullout specimens $(150 \mathrm{~mm} \times 150 \mathrm{~mm} \times 150 \mathrm{~mm})$ were used to test the bonding properties of aerated concrete and different glass fiber, and the details are listed in Figure 2.

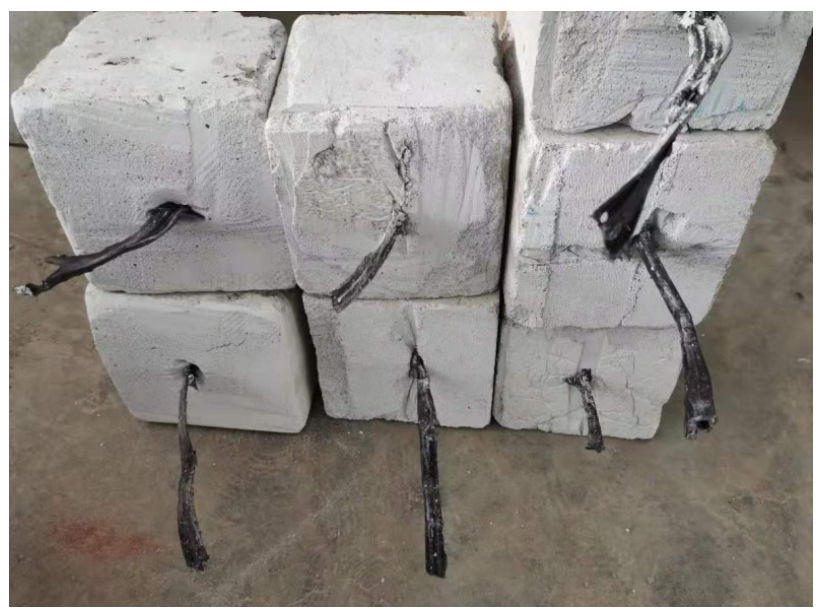

Figure 2: Pullout specimens

\subsection{Loading test}

The cubic specimens and pullout specimens were tested in the electro-hydraulic servo machine, and the applied load was collected by the computer. Pullout test setup is shown in Figure 3.

\section{Results}

\subsection{Cubic compressive strength}

The gas generating agent will generate a large number of bubbles inside the concrete, thereby reducing the dry den-

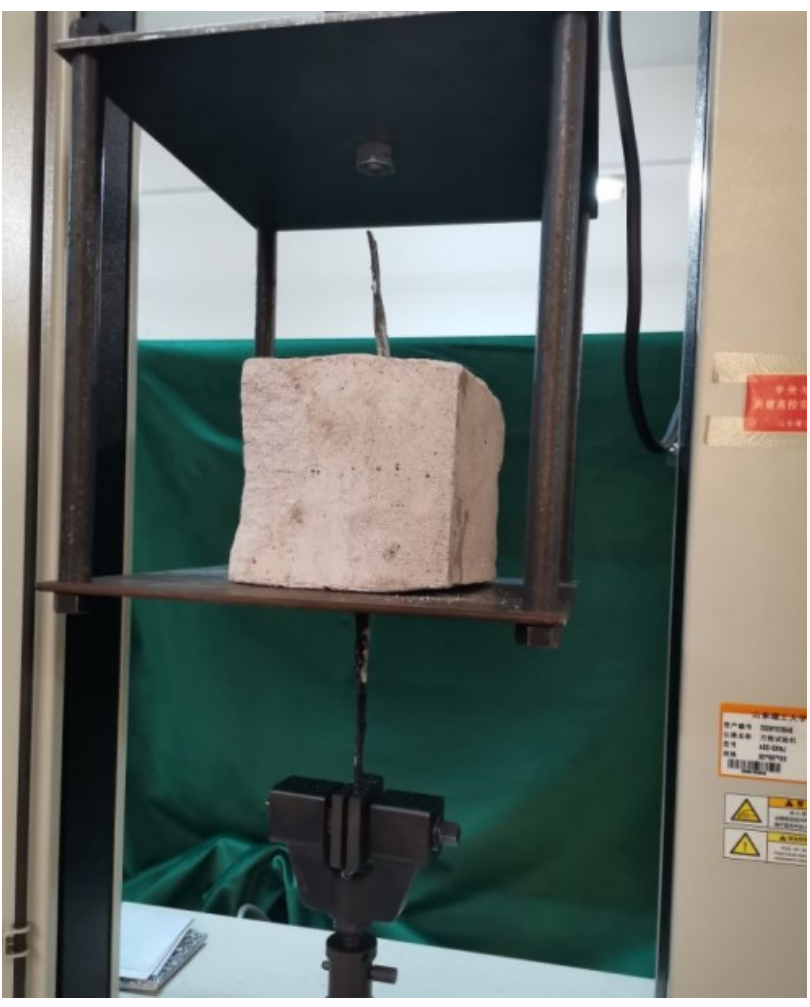

Figure 3: Pullout test setup

sity and thermal conductivity of the specimen. However, it will also reduce the compressive strength of aerated concrete, so an appropriate amount of gas generating agent has an important effect on aerated concrete. Aluminum powder and ferrosilicon alloy powder are currently commonly used gas generating agents.

\subsubsection{Influence of aluminum powder on cubic compressive strength}

The change curve of the compressive strength of aerated concrete with the amount of aluminum powder is shown in the Figure 4. It can be seen that the compressive strength of aerated concrete decreased with the increase of aluminum powder content, this is consistent with Zhang [19]. The reason is that as the amount of aluminum powder increases, the amount of gas generated in the paste is greater, and more pores will be generated inside the paste, which reduces the hydration products per unit volume, and the internal skeleton structure of the concrete becomes weaker, which reduce the compressive strength of aerated concrete [19].

In addition, when the aluminum powder content was less than $0.08 \%$, the concrete strength of aerated concrete decreased slowly; when the aluminum powder content 
was greater than $0.08 \%$, the concrete strength of aerated concrete decreased rapidly. Therefore, the aluminum powder content should not be greater than $0.08 \%$.

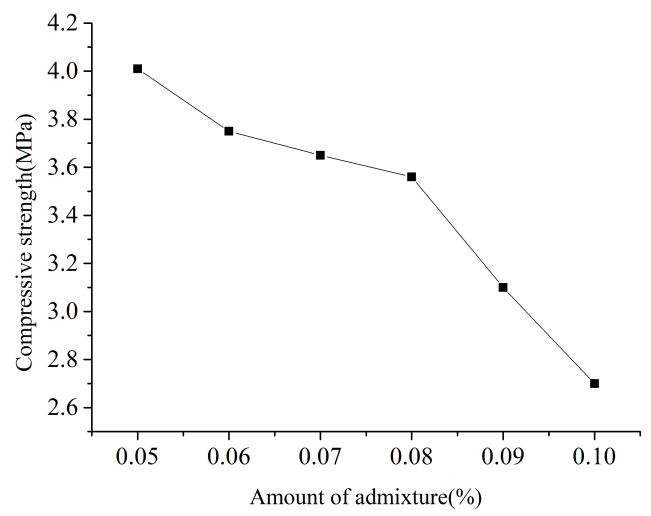

Figure 4: Compressive strength versus aluminum powder content

\subsubsection{Ferrosilicon alloy powder on cubic compressive strength}

The change curve of the compressive strength of aerated concrete with the amount of ferrosilicon alloy powder is shown in the Figure 5. It can be seen that the compressive strength of aerated concrete first increased and then decreased with the increase of ferrosilicon alloy powder content. When the ferrosilicon alloy powder content is $30 \%$, the strength of aerated concrete is the highest.

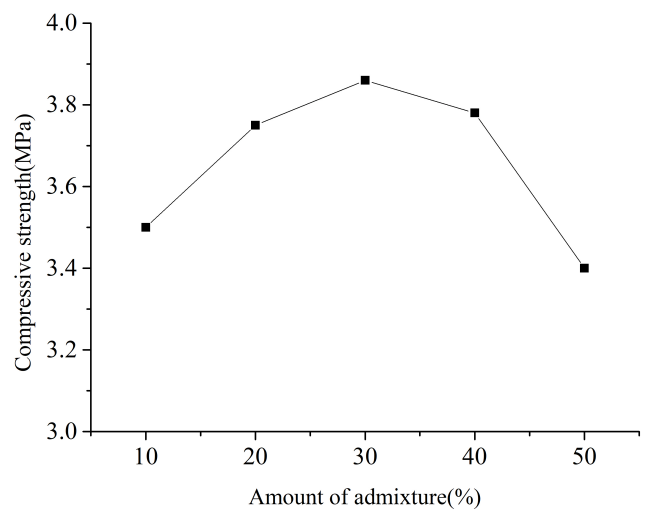

Figure 5: Compressive strength versus ferrosilicon alloy powder content

\subsection{Bonding performance of aerated concrete and glass fiber}

The failure modes of specimens were fiber fracture failure, and the fibers were not pulled out from the aerated concrete.

The change curve of the bonding strength of aerated concrete specimens with the amount of aluminum powder is shown in the Figure 6 . The change curve of the bonding strength of aerated concrete specimens with the amount of ferrosilicon alloy powder is shown in the Figure 7.

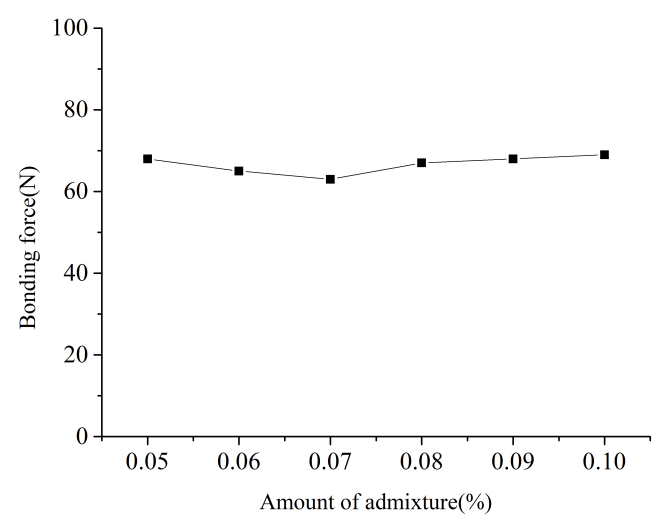

Figure 6: Bonding force versus aluminum powder content

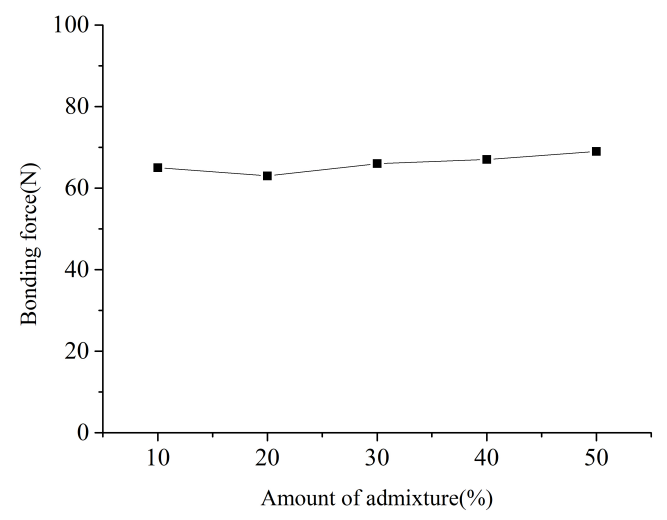

Figure 7: Bonding force versus ferrosilicon alloy powder content

It can be seen that the aluminum powder and ferrosilicon alloy powder did not affect the bonding strength of aerated concrete specimens. The reason is that the glass fiber was broken before the maximum bond strength was 
reached. This means that there is good bonding performance between the glass fiber and the aerated concrete.

In addition, with the continuous development of building materials, scholars hope to apply more technologies to building materials: Liu [20] studied the addition of graphene oxide to improve the ultra-early strength of sulphoaluminate cement-based materials. Su [21, 22] studied the possibility of using recycled concrete in engineering.

\section{Conclusions}

(1) The compressive strength of aerated concrete decreased with the increase of aluminum powder content.

(2) The compressive strength of aerated concrete first increased and then decreased with the increase of ferrosilicon alloy powder content.

(3) The failure modes of specimens were fiber fracture failure, and the fibers were not pulled out from the aerated concrete. There is good bonding performance between the glass fiber grille and the aerated concrete.

Funding information: The authors state no funding involved.

Author contributions: All authors have accepted responsibility for the entire content of this manuscript and approved its submission.

Conflict of interest: The authors state no conflict of interest.

\section{References}

[1] Alexanderson J. Relations between structure and mechanical properties of autoclaved aerated concrete. Cem Concr Res. 1979;9:507-514.

[2] Petrov I, Schlegel E. Application of automatic image analysis for the investigation of autoclaved areated concrete structure. Cem Concr Res, 1994;24:830-840.

[3] Prim P, Witmann FH. Structure and water absorption of aerated concrete. Proceedings of the RILEM International Symposium on Autoclaved Aerated Concrete. 1983;6:55-69.

[4] Wang S D. Study on preparation and properties of nonautoclaved aerated concrete. Southeast University, 2016. (in Chinese)

[5] Robler M, Odler I. Investigations on the relationship between porosity structure and strength of hydrated portland cement pastes III. Effect of clinker composition and gypsum addition. Cem Concr Res, 1985;15:320-330.
[6] Ho. G C. Porosity-strength considerations for cellular concrete. Cem Concr Res, 1972;2:91-100.

[7] Jorge L. Varela, Jennifer E. Tanner, Richard E. K lingner. Development of seismic force red-uction and displacement amplification factors for autoclaved aerated concrete structures. Earthq. Spectra, 2006;22(1):267-286.

[8] Tomá. Coupled shrinkage and damage analysis of autoclaved aerated concrete. Appl. Math. and Comput, 2015;267:427-435.

[9] Yu J H. Research on seismic performance of new lightweight aerated concrete load-bearing masonry. Tianjin University, 2008. (in Chinese)

[10] Jin Y, Cheng C Y. Experimental study on the performance of joints of autoclaved aerated concrete wall panels. Wall material innovation and building energy saving, 2009;(2):34-37+3. (in Chinese)

[11] Leng N, Zhao C W. Finite element analysis of autoclaved aerated concrete slab. Heilongjiang Science and Technology Information, 2010;(2):280. (in Chinese)

[12] Wu H G, Zhao J. Seismic performance analysis of aerated concrete block masonry walls with windows. World Earthquake Engineering, 2012;28 (1):33-38. (in Chinese)

[13] Zeng H. Experimental study on the stress-strain constitutive relationship of autoclaved fly ash-sand aerated concrete and its masonry mechanical properties. Changsha University of Science and Technology, 2013. (in Chinese)

[14] Li X D. Design and research of lightweight autoclaved sand aerated concrete wall panel. Chang'an University, 2014. (in Chinese)

[15] Zhang G W, Zhang P, Chen B S, Chen P. Study on displacement ductility of autoclaved aerated concrete slab. Industrial Construction,2017;47 (12):106-110+126. (in Chinese)

[16] Li G, Zhuang Z, Lv Y, et al. Enhancing carbonation and chloride resistance of autoclaved concrete by incorporating nano$\mathrm{CaCO}_{3}$. Nanotechnol. Rev. 2020;9(1):998-1008.

[17] Guo Z, Zhu Q, Wu W, et al. Research on bond-slip performance between pultruded glass fiber-reinforced polymer tube and nano- $\mathrm{CaCO}_{3}$ concrete. Nanotechnol. Rev. 2020;9(1):637-649.

[18] Ministry of Industry and Information Technology of the People's Republic of China. Quicklime for silicate building products JC/T621-2009, 2009. (in Chinese)

[19] Zhang H L. Research on the performance of aerated concrete self-insulating wall in severe cold area. Harbin Institute of Technology, 2019. (in Chinese)

[20] Liu Y, Jia M, Song C, et al. Enhancing ultra-early strength of sulphoaluminate cement-based materials by incorporating graphene oxide. Nanotechnol. Rev., 2020;9(1):17-27.

[21] Su T, Wang C, Cao F, et al. An overview of bond behavior of recycled coarse aggregate concrete with steel bar. Rev. Adv. Mater. Sci., 2021;60(1):127-144.

[22] Su T, Wu J, Zou Z, et al. Bond performance of steel bar in RAC under salt-frost and repeated loading. J. Mater. Civil. Eng., 2020;32(9):04020261. 